\title{
Changes of Absolute Thermoelectric Power and Electrical Resistivity in Pure Iron by Cold Rolling and Subsequent Isochronal Annealing*
}

\author{
By Hideo ABE, ,* Takeshi SUZUKI** and Hiroshi HOSHINA***
}

\begin{abstract}
Synopsis
Changes in absolute thermoelectric power, electrical resistivity and hardness in the processes of cold rolling at room temperature and subsequent isochronal annealing have been observed in Johnson-Matthey's pure iron and electrolytic iron preliminarily decarburized and denitrided. It is supposed that vacancies most of which have been formed in the later stages of cold rolling annihilate on isochronal annealing from $140^{\circ} \mathrm{C}$ up to $240^{\circ} \mathrm{C}$ in Johnson-Matthey's iron, and from $160^{\circ} \mathrm{C}$ up to $200^{\circ} \mathrm{C}$ in electrolytic iron. Softening by recrystallization commences at about $340^{\circ} \mathrm{C}$ in Johnson-Matthey's iron, and at about $360^{\circ} \mathrm{C}$ in electrolytic iron. The gradients of the absolute thermopower vs. electrical conductivity plots at $0^{\circ} \mathrm{C}$ are obtained for several stages of cold rolling and annealing processes. The gradient corresponding to the increase and the decrease in dislocation density is $500 \pm 100 \mu \mathrm{V} \cdot \mu \Omega \cdot \mathrm{cm} \cdot \mathrm{deg}^{-1}$ for Johnson-Matthey's iron, and is $400 \mu \mathrm{V} \cdot \mu \Omega \cdot \mathrm{cm} \cdot \mathrm{deg}^{-1}$ for electrolytic iron. The gradient characteristic to carbon and nitrogen in solution is estimated to be $130 \pm 50 \mathrm{nV} \cdot \mathrm{u} \Omega \cdot \mathrm{cm} \cdot \mathrm{deg}^{-1}$.
\end{abstract}

\section{Introduction}

A series of experiments have been made on the thermoelectric power as a tool for investigating such processes as work-hardening, recovery, recrystallization, precipitation and other phase changes in iron and iron-base alloys. ${ }^{1,2)}$ Part of the results obtained for the precipitation of carbides and nitrides in a lowcarbon aluminium-killed steel has been reported in a previous paper. ${ }^{1)}$ The present paper concerns with a study of the changes in thermopower and electrical resistivity in pure iron by cold rolling and subsequent isochronal annealing.

In a case where the conduction electrons in a metallic material are scattered by the phonons and the impurity atoms or the lattice defects of one kind, the electron-diffusion thermopower $S^{e}$ is given by the following expression which can be derived under several assumptions and approximations., ${ }^{3,4}$

$$
S^{e}=S_{i}^{e}+\left(S_{0}^{e}-S_{i}^{e}\right) \rho_{0} /\left(\rho_{0}+\Delta \rho\right) .
$$

Where $S_{0}^{e}$ and $\rho_{0}$ are the thermopower and the resistivity of a perfect crystal of the pure metal, $S_{i}^{e}$ is the thermopower characteristic to the impurity or the lattice defect which causes an increase $\Delta \rho$ in the resistivity. Equation (1) shows that a plot of thermopower $S^{e} v s$. conductivity $1 /\left(\rho_{0}+\Delta \rho\right)$ at constant temperature should lie on a straight line. This relationship has been called as the Nordheim-Gorter rule.

Equation (1) might not hold in the case of ferromagnetic iron, however, since its thermopower contains the phonon-drag and the magnon-drag components. Blatt et al. ${ }^{5)}$ observed that the thermopower of pure iron exhibited a large positive peak at around $200 \mathrm{~K}$ and concluded that the magnon-drag played a dominant role even at room temperature. They discounted phonon-drag effect on the basis of the observation on the effects of cold working and of alloying. However, by making a comparison of all possible sources of the $200 \mathrm{~K}$ peak, Blatt ${ }^{6)}$ recently concluded that the phonon-drag ought not to be neglected. The physical interpretation of the thermoelectric power of iron is still in confusion and the spin-orbit scattering, the electron-electron scattering, the phonon-drag and the magnon-drag have been listed as possible origins of the peak at $200 \mathrm{~K} .{ }^{7)}$ Thus, the Nordheim-Gorter rule for the electron-diffusion thermopower is not necessarily expected to hold in ferromagnetic iron.

However, in a dilute binary solid solution of iron or in pure iron containing a low density of lattice defects of one kind, both the thermopower and the conductivity may approximately be a linear function of the solute concentration or the density of lattice defect, and, in such a case, the thermopower vs. conductivity plot will approximately lie on a straight line. The gradient of the straight line is expected to have a value characteristic to the solute atom or the lattice defect under investigation. Thus, for example, the thermopower $v s$. conductivity plot for the process of precipitation of cementite from low-carbon steel can be expected to lie on a straight line with a gradient characteristic to the carbon in solution, if any other unexpected reaction does not take place simultaneously.

In a real metallurgical process in which more than two kinds of reaction might proceed simultaneously, the thermopower vs. conductivity plot would lie on a curved line, but in the following special cases, an approximately linear relation between the thermopower and the conductivity could be expected:

(1) When one of the reactions predominently contributes both to the thermopower and to the conductivity.

(2) When several reactions proceed in constant proportion.

(3) When the gradients of the lines characteristic to all of the reactions involved are close to each other. Thus, in order to define the nature of a process under investigation from the observed gradient of the thermopower $v s$. conductivity plot, a large number of basic data on the thermopowers in various alloy systems are required. In a case where the thermopower $v s$. con-

* Originally published in Tetsu-to-Hagané, 65 (1979), 399, in Japanese. English version received on December $20,1978$.

** Department of Metallurgy and Materials Science, The University of Tokyo, Hongo, Bunkyo-ku, Tokyo 113.

*** The Graduate School, The University of Tokyo. 
ductivity plot for any given process could be divided into several linear portions, the process may at least be said to consist of different reactions which corresspond to these respective linear portions. ${ }^{2}$ ) In other words, the thermopower $v s$. conductivity plot will be a very useful means for separating various reactions that take place during an unknown process under investigation.

The results presented here are those obtained from one of the recent experiments to present a number of basic data for the applications of the thermopower vs. conductivity plot to various processes that occur in iron and iron-base alloys. The changes in thermopower and resistivity of pure iron due to the lattice defects induced by cold working have been the main interest of this study and special attention has been given to the multiplication and annihilation of dislocations.

The grain size and the impurities might have considerable influences on the formation of lattice defects. To inquire a possibility of getting some information concerning the influences of grain size and impurities, two kinds of high-purity iron; one supplied from the Johnson-Matthey \& Co. and another, commercially available electrolytic iron, were used as the starting materials for this study.

\section{Experimental}

\section{Specimens}

The original specimens of pure iron supplied by the Johnson-Matthey \& Co. and of electrolytic iron, whose chemical compositions were as given in Table 1 , were preliminarily cold rolled to a final thickness of $0.53 \mathrm{~mm}$ and to $0.58 \mathrm{~mm}$, respectively. Test-pieces of $4 \mathrm{~mm}$ wide and $120 \mathrm{~mm}$ long (Fig. 1) were cut from these cold-rolled sheets.

The test-piece of Johnson-Matthey's iron was annealed at $700^{\circ} \mathrm{C}$ for $26 \mathrm{hr}$ in a wet-hydrogen flowing furnace for removing carbon and nitrogen, subsequently annealed at $700^{\circ} \mathrm{C}$ for $48 \mathrm{hr}$ in a flowing dryhydrogen atmosphere and slowly cooled in the furnace. Hereinafter, the test-piece of Johnson-Matthey's pure iron thus prepared is called as "J.M.-iron".

The test-piece of electrolytic iron was subjected to two-stage annealing of $800^{\circ} \mathrm{C}$ for $2 \mathrm{hr}$ and $700^{\circ} \mathrm{C}$ for $44 \mathrm{hr}$ in wet-hydrogen, subsequently annealed at $700^{\circ} \mathrm{C}$ for $40 \mathrm{hr}$ in dry-hydrogen and slowly cooled in the

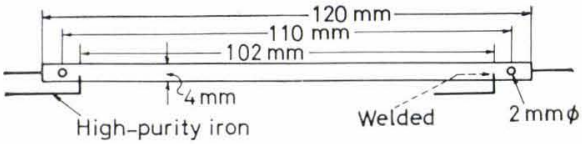

Fig. 1. Test-piece furnace. The electrolytic iron test-piece thus prepared is called hereinafter as "Elect.-iron".

Commercially supplied hydrogen-gas was purified by passing through a palladium-catalyzer tube, and the 'wet-hydrogen' was produced by bubbling through water kept at $30^{\circ} \mathrm{C}$, while the 'dry-hydrogen ' was obtained by passing through a copper tube immersed in liquid nitrogen.

The microstructures of these pure iron test-pieces after the purification treatments stated above were as shown in Photo. 1. The mean grain size given in diameter was $172 \mu \mathrm{m}$ in J.M.-iron, and was $34 \mu \mathrm{m}$ in Elect.-iron. The ratio of the electrical resistivity at $0^{\circ} \mathrm{C}$ to that at liquid nitrogen temperature was 14.9 for J.M.-iron, and was 13.8 for Elect.-iron.

Reference test-pieces of the same materials subjected to the same purification treatments as stated above were aged for a long time at several temperatures within a range between $300^{\circ} \mathrm{C}$ and $50^{\circ} \mathrm{C}$. Electrical resistivity measurements on these aged test-pieces suggested $^{8,9)}$ that the J.M.-iron and Elect.-iron test-pieces after the purification treatments contained total amounts of carbon at $0.5 \mathrm{wt} . \mathrm{ppm}$ and $2.8 \mathrm{wt} . \mathrm{ppm}$ levels, respectively.

\section{Procedures}

Processing for both specimens was cold rolling at room temperature followed by isochronal annealing.

After removing the leads for electrical measurements, the J.M.-iron and the Elect.-iron test-pieces
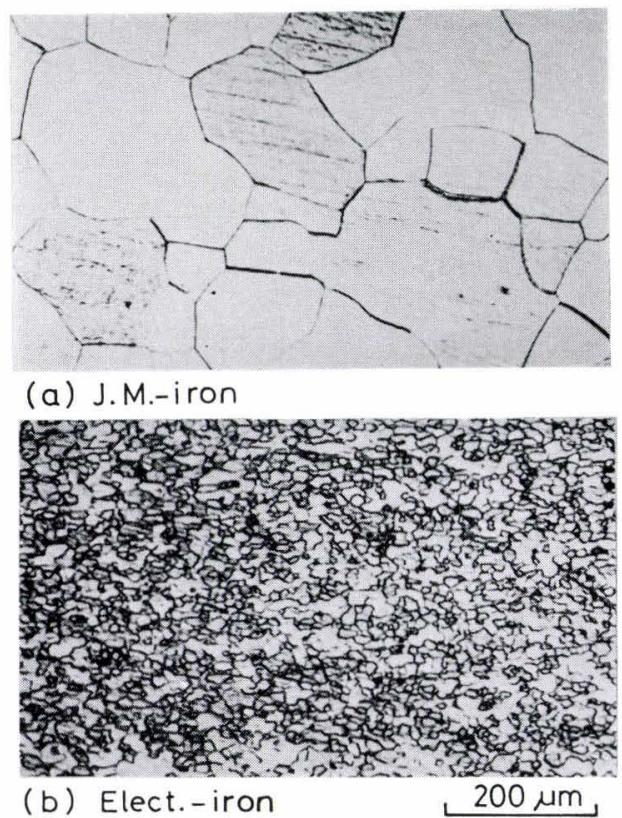

Photo. 1. Optical micrographs for (a) Johnson-Matthey's pure iron and (b) electrolytic iron, both after the purification treatments described in the text

Table 1. Chemical composition of the starting materials (wt \%)

\begin{tabular}{l|cccccccc}
\hline & $\mathrm{C}$ & $\mathrm{N}$ & $\mathrm{O}$ & $\mathrm{Si}$ & $\mathrm{Mn}$ & $\mathrm{P}$ & $\mathrm{S}$ & $\mathrm{Cu}$ \\
\hline Johnson-Matthey's iron & 0.005 & 0.0202 & 0.0084 & 0.0003 & 0.0001 & - & - & 0.0001 \\
\hline Electrolytic iron & 0.005 & - & - & 0.005 & 0.005 & 0.004 & 0.005 & 0.004 \\
\hline
\end{tabular}


were cold rolled at room temperature by successive passes of low reductions to a total reduction of about $85 \%$ in thickness. The test-pieces, similar to that shown in Fig. 1, were newly prepared after each pass of cold rolling. After keeping for about one month at room temperature, the test-pieces prepared from the $85 \%$-rolled tapes were isochronally annealed for 30 -min periods in 20 -deg intervals from $40^{\circ} \mathrm{C}$ up to $540^{\circ} \mathrm{C}$. Each test-piece was sealed in an evacuated tube $\left(<10^{-3}\right.$ Torr $)$ of Pyrex glass and, after each step of annealing, the test-piece sealed in the glass tube was quenched into ice-water.

After each pass of cold rolling and after each step of isochronal annealing, measurements were made on the hardness (observed at 10 points, with $100 \mathrm{~g}$ load), the electrical resistivities at $0^{\circ} \mathrm{C}$ and at liquid nitrogen temperature, and the thermoelectric power at $0^{\circ} \mathrm{C}$. In addition, the microstructures at several stages of cold rolling and annealing were observed by transmission electron microscopy using a $150 \mathrm{kV}$ electron microscope.

To eliminate the errors in observed values of resistivity due to inaccuracy of the size factor measurements, corrections were made by assuming that Matthiessen's rule for electrical resistivity is approximately obeyed. The electrical resistance of each test-piece was measured by the four-terminal potentiometer method, precautions being taken to control the temperature of the test-piece and the electrical current (0.50 A for the measurement at liquid nitrogen temperature, and $0.30 \mathrm{~A}$ for $0^{\circ} \mathrm{C}$ ). The current through the test-piece was kept constant by keeping the potential drop across a standard specimen connected in series at a constant value. Thinner test-pieces of higher cold reductions were slightly influenced by Joule's heat due to a high current density, but its influence was negligible for the present purpose.

A pictorial diagram of the apparatus used for the thermopower measurement is shown in Fig. 2. The upper half is a high-temperature oil bath, the maximum temperature being approximately $24^{\circ} \mathrm{C}$, and the lower half is a low-temperature flask filled with icewater. The top terminals (hot-junctions) of the testpiece and the standard-piece are connected thermally onto an electrically insulated copper plate and kept at constant temperature within $\pm 0.1^{\circ} \mathrm{C}$ or better. The bottom junction (cold-junction) of the couple of the test-piece and the standard-piece connected tightly by a brass screw is inserted into a narrow hole of an electrically insulated copper block immersed in the icewater. The temperature difference $\Delta T$ between the top terminals and the bottom junction was measured by a copper-constantan thermocouple kept pointcontacts by synthetic resin at the positions shown in Fig. 2. An electrolytic iron test-piece cold rolled to a thickness of $0.58 \mathrm{~mm}$ and aged at $50^{\circ} \mathrm{C}$ for 7 days was used as the standard-piece. The temperature dependence of the absolute thermopower of this standardpiece was nearly equal to those of all the test-pieces within the temperature range between $0^{\circ} \mathrm{C}$ and $24^{\circ} \mathrm{C}$. After the whole system had nearly attained thermal equilibrium, the thermo-e.m.f. of the couple was meas-

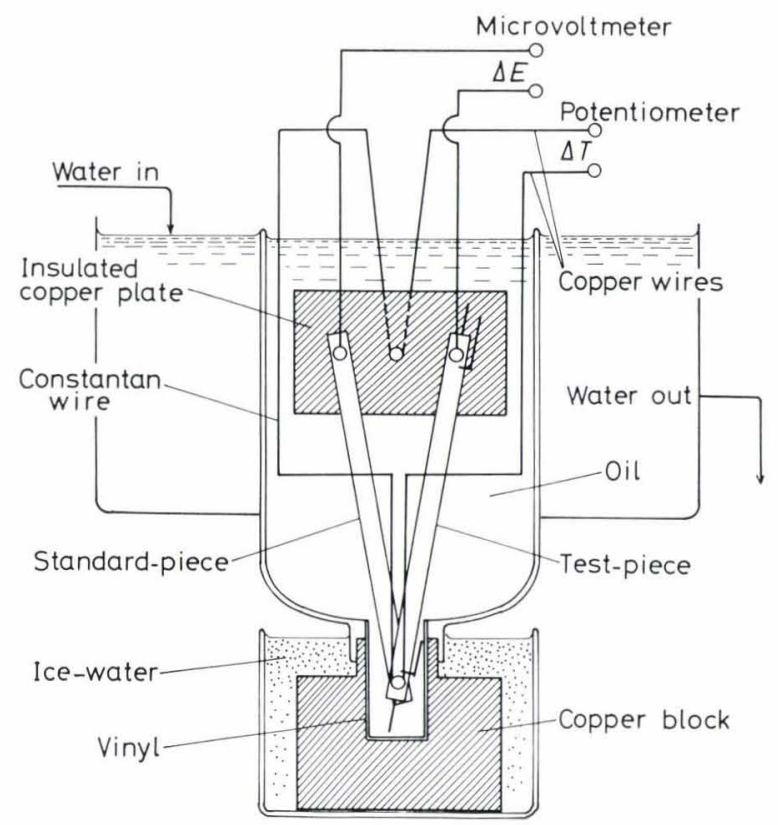

$$
\Delta S=\Delta E /\lrcorner T
$$

Fig. 2. Pictorial diagram of the apparatus used for the measurement of thermoelectric power $\Delta S$.

ured by a high-sensitivity microvoltmeter with a high input resistance $(2 \mathrm{M} \Omega$ ). The thermopower of the testpieces $J S$ relative to the standard-piece was obtained by simply dividing the thermo-e.m.f. $\Delta E$ by the temperature difference $J T$. Preliminary measurements of the thermo-e.m.f. $\Delta E$ at intervals of about $1^{\circ} \mathrm{C}$ as the temperature of the hot-junctions was raised up to $24^{\circ} \mathrm{C}$ showed a linear relation between $\Delta E$ and $\Delta T$, so that the temperature difference as high as $24^{\circ} \mathrm{C}$ could be allowed to determine the thermopower within $\pm 0.01 \mu \mathrm{V} / \mathrm{deg}$. The absolute thermopower of the standard-piece at $0^{\circ} \mathrm{C}$ was found to be $+14.5 \mu \mathrm{V} / \mathrm{deg}$, which was obtained from the thermopower measurement relative to pure lead of $99.999 \mathrm{wt} \%$ purity. Using this value, the observed values of thermopower were converted to the absolute values.

\section{Results and Discussion}

\section{Cold Rolling Process}

The work-hardening data for J.M.-iron and Elect.iron shown in Fig. 3 were obtained by cold rolling at room temperature by successive passes of low reductions to a total reduction of about $85 \%$ in thickness. The abscissa is given by $\log \left(L / L_{0}\right)$, where $L_{0}$ is the initial length of the specimen and $L$ is the length after cold rolling. The hardness of J.M.-iron exhibits larger scatter with increasing cold reduction. This scatter seems to arise from the large initial grain size of the specimens. The work-hardening of J.M.-iron shows a tendency to saturate above around $50 \%$ reduction. The saturation in work-hardening may partly be due to the effect of texture formation which was prominent in the reduction range higher than about $50 \%$. The work-hardening in Elect.-iron is much more pronounced and the scatter in the hardness data is 


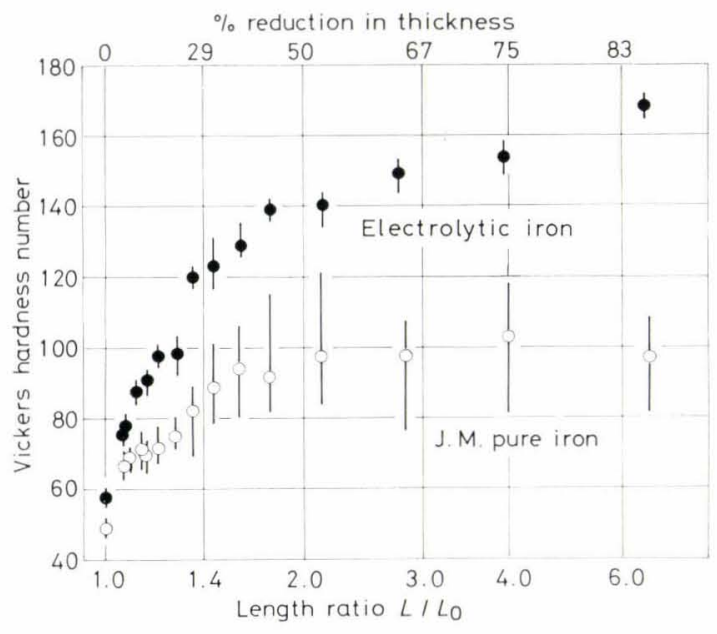

$L_{0}, L:$ the lengths of the test-piece before and after cold rolling

Fig. 3. Variations in hardness on cold rolling at room temperature by successive passes of low reductions to a total reduction of about $85 \%$ in thickness

considerably smaller than in the case of J.M.-iron. Such differences in work-hardening behaviour may be accounted for by the differences in grain size and impurity content of these two specimens.

In Fig. 4, the absolute thermopower at $0^{\circ} \mathrm{C}$ and the electrical resistivity at liquid nitrogen temperature for J.M.-iron are plotted against $\log \left(L / L_{0}\right)$. The thermopower decreases, while the resistivity correspondingly increases with increasing cold reduction. Here, the scale of the ordinate for thermopower in Fig. 4, and also those in the following figures, are inversed for the convenience to compare with the resistivity data. The increase in resistivity by $85 \%$ cold reduction is $0.05 \mu \Omega \cdot \mathrm{cm}$, which corresponds to a dislocation density of approximately $5 \times 10^{10} \mathrm{~cm}^{-2}$ if the whole increase is assumed to be only due to dislocations. ${ }^{10)}$ Figure 4 indicates that the increase in dislocation density continues even in the reduction range higher than $50 \%$, whereas the hardness data shown in Fig. 3 show the saturation of work-hardening in J.M.-iron above $50 \%$ reduction.

Plots of absolute thermopower and electrical resistivity for Elect.-iron against $\log \left(L / L_{\mathbf{0}}\right)$ are shown in Fig. 5. The increase in dislocation density of approximately $1.1 \times 10^{11} \mathrm{~cm}^{-2}$ after $85 \%$ cold reduction calculated under the same assumption as stated above is about twice of that for J.M.-iron. From the plot of thermopower in Fig. 5, the cold rolling process of Elect.-iron can be divided into three regions, though they are not clear in the resistivity plot. The first region of rapid decrease in thermopower is followed by the second one of slower decrease. The third region that commences at around $40 \%$ reduction is characterized by a peculiar variation in thermopower. It is interesting to note that the onset of the third region at $40 \%$ reduction could also be noticed in the hardness data for Elect.-iron shown in Fig. 3. Discussion of the meanings of these three regions will be given later.

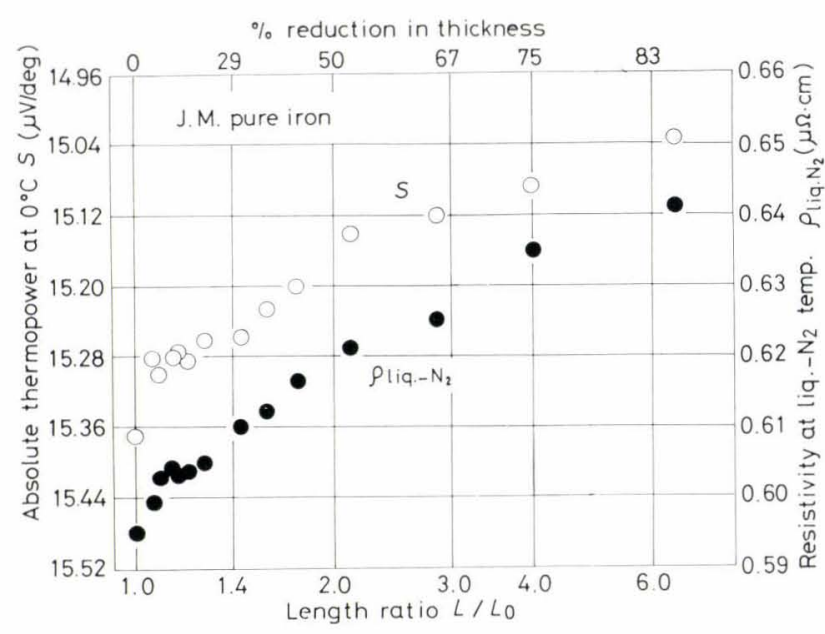

Fig. 4. Changes in the absolute thermopower and electrical resistivity of J.M.-iron by cold rolling

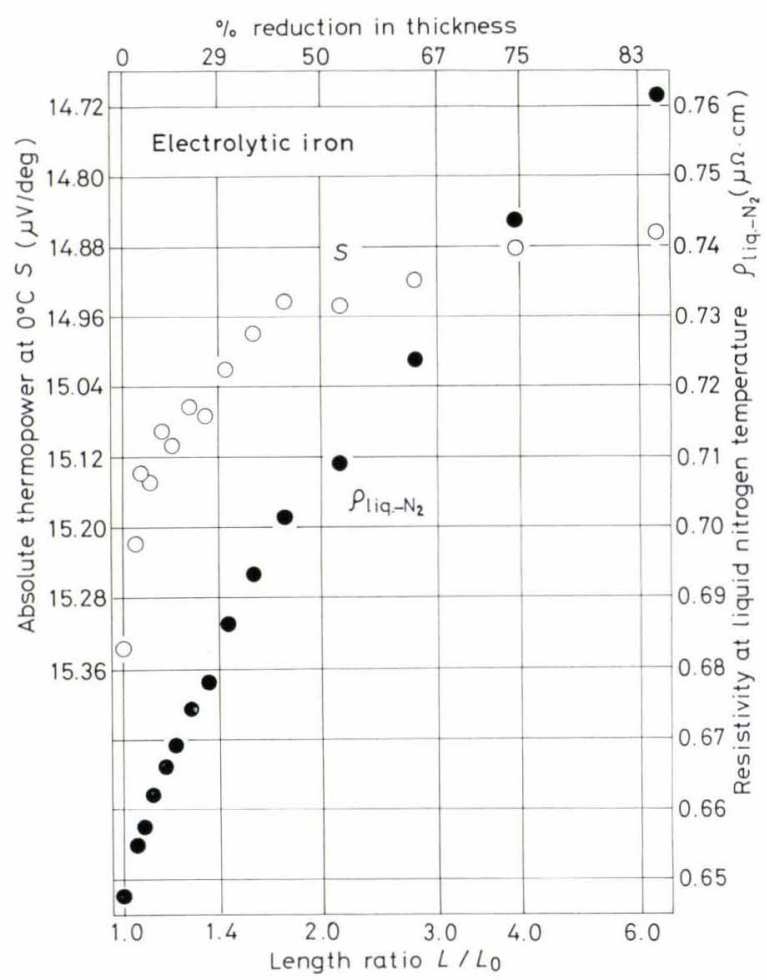

Fig. 5. Changes in the absolute thermopower and electrical resistivity of Elect.-iron by cold rolling

\section{Isochronal Annealing Process}

The test-pieces prepared from the $85 \%$-rolled tapes were left at room temperature for about one month and subjected to isochronal annealing at $30 \mathrm{~min} / 20^{\circ} \mathrm{C}$ step from $40^{\circ} \mathrm{C}$ up to $540^{\circ} \mathrm{C}$. Figure 6 shows the changes in hardness with the temperature of the isochronal annealing. The scatter in hardness data is large in J.M.-iron in the low-temperature range below $300^{\circ} \mathrm{C}$, becoming much smaller on annealing above $340^{\circ} \mathrm{C}$ where a remarkable softening takes place. This softening was found to be accompanied with recrystallization. In Elect.-iron, softening by recrystallization occurs on annealing above $360^{\circ} \mathrm{C}$.

In Photo. 2, the transmission electron micrographs for J.M.-iron isochronally annealed up to $100^{\circ} \mathrm{C}, 300^{\circ} \mathrm{C}$, 


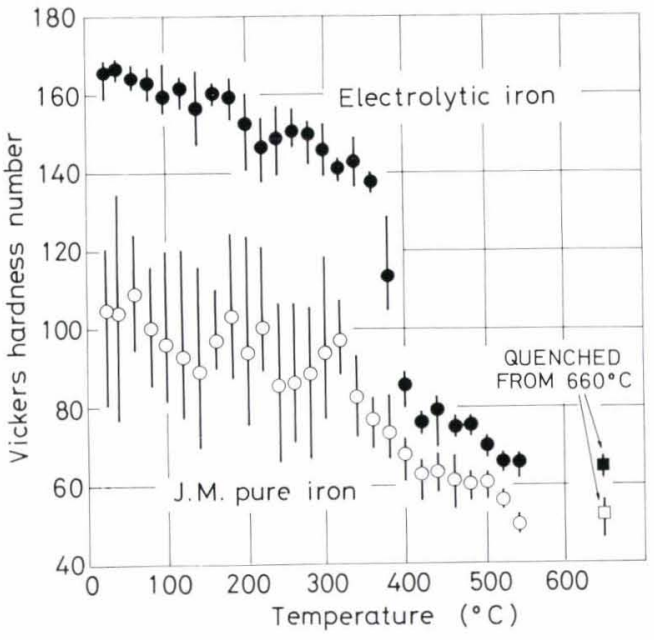

$\square$, $\mathbf{a}$ : the data after quenching from $660^{\circ} \mathrm{C}$

Fig. 6. Variations in hardness on isochronal annealing for 30-min period at each of the temperatures specified (about 20-deg intervals) $420^{\circ} \mathrm{C}$ and $540^{\circ} \mathrm{C}$ are shown together with an electron diffraction pattern from a dislocation-free area in the $100^{\circ} \mathrm{C}$-annealed specimen. The microstructure after annealing up to $100^{\circ} \mathrm{C}$ (Photo. 2 (a)) is very similar to that of the cold-rolled state, and it contains large dislocation-free regions as shown in Photo. 2 (b). The diffraction pattern from one of these regions (Photo. 2 (c)) reveals the Kikuchi lines. Thus, the large scatter in hardness data of J.M.-iron can be attributed to the macroscopic inhomogeneity in dislocation density arising from the large grain size of the test-piece before cold rolling. On annealing up to $300^{\circ} \mathrm{C}$, recrystallized grains growing into the deformed matrix of a high dislocation density can be observed as shown in Photo. 2 (d). The hardness data of J.M.-iron shown in Fig. 6 indicate an arrest of softening at around $420^{\circ} \mathrm{C}$. Photo. 2 (e) shows that there still remain high dislocation-density regions after annealing up to $420^{\circ} \mathrm{C}$. Even after annealing up to $540^{\circ} \mathrm{C}$, dislocation network as shown in Photo. 2 (f) can be observed locally.

Photographs 3 (a), (b), (c) and (d) are the micro-
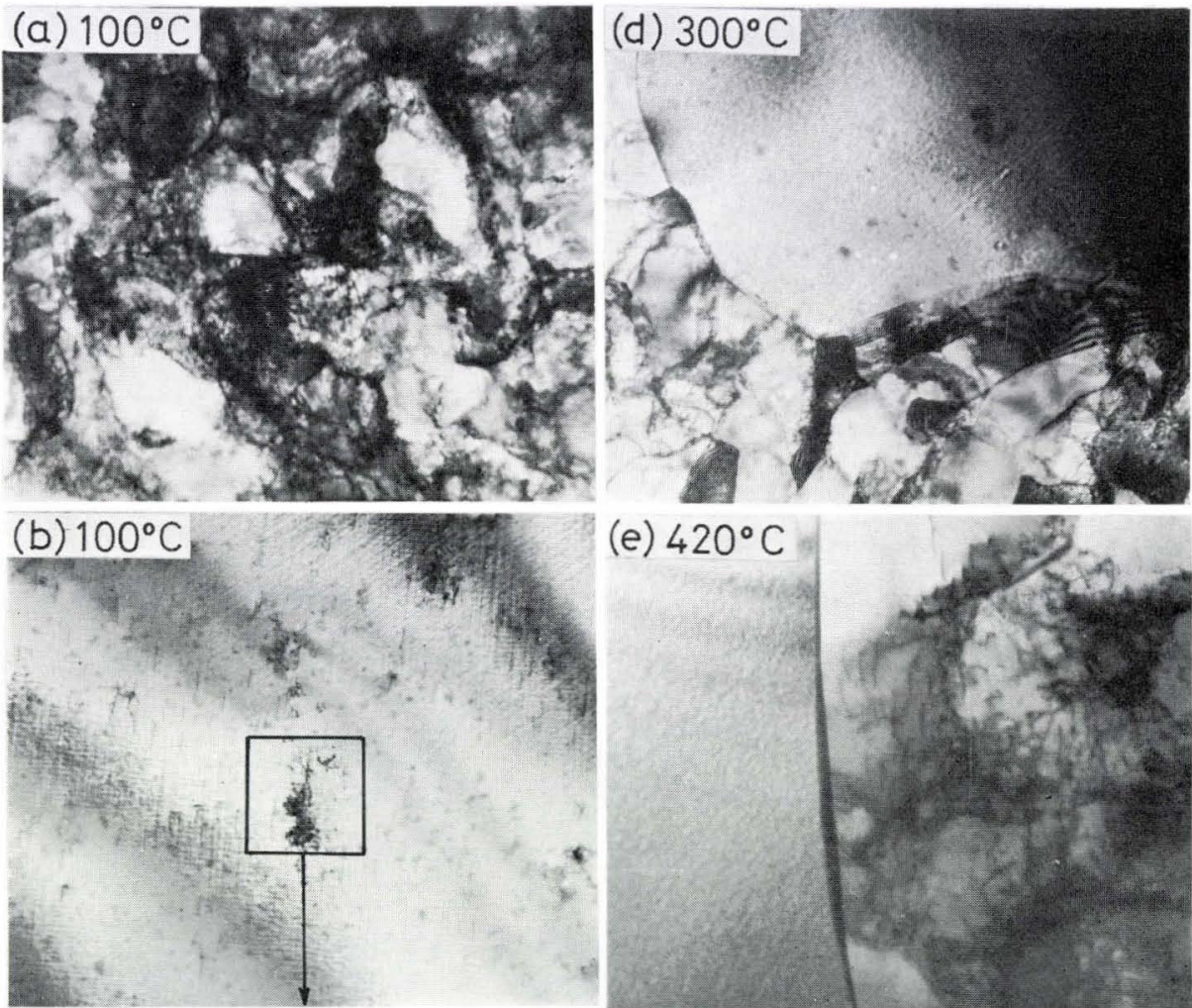

(e) $420^{\circ} \mathrm{C}$
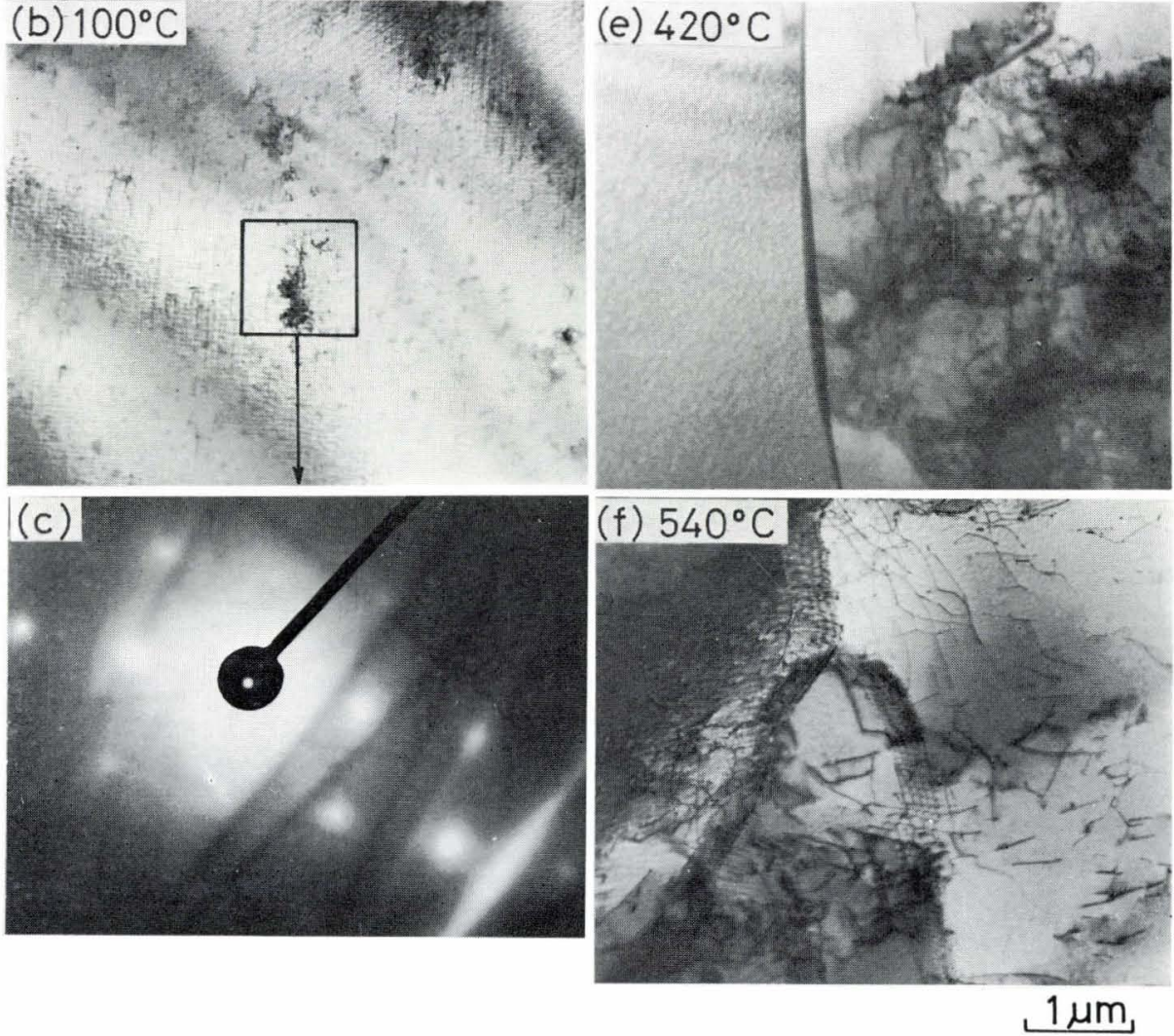

Photo. 2.

Transmission electron micrographs for J.M.-iron isochronally annealed at $30 \mathrm{~min} / 20^{\circ} \mathrm{C}$ step up to $(\mathrm{a}-\mathrm{b}) 100^{\circ} \mathrm{C}$, (d) $300^{\circ} \mathrm{C}$, (e) $420^{\circ} \mathrm{C}$ and (f) $540^{\circ} \mathrm{C}$. Photo. (c) shows the electron diffraction pattern from the selected area indicated in Photo (b). 

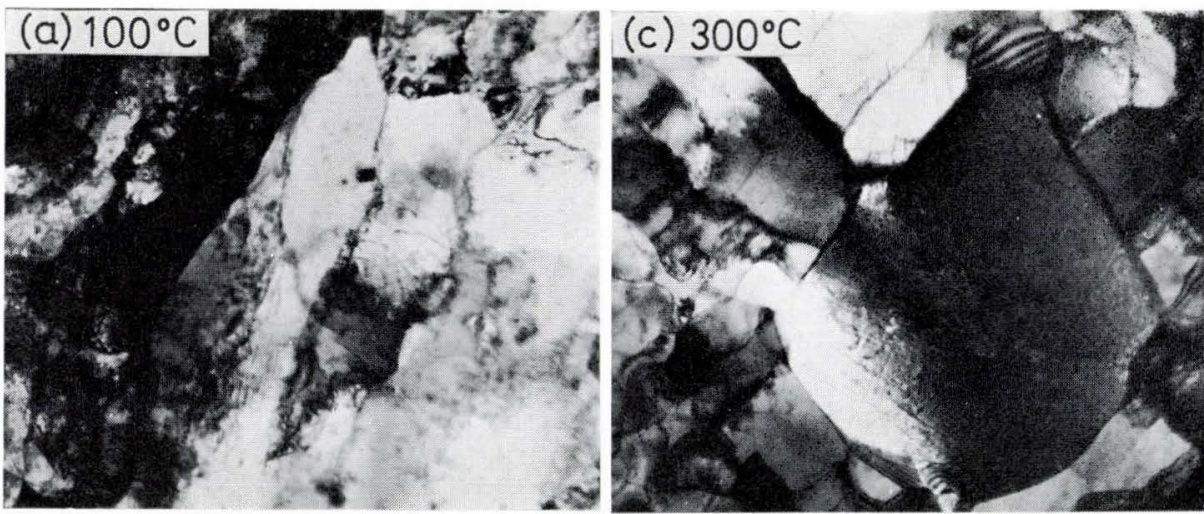

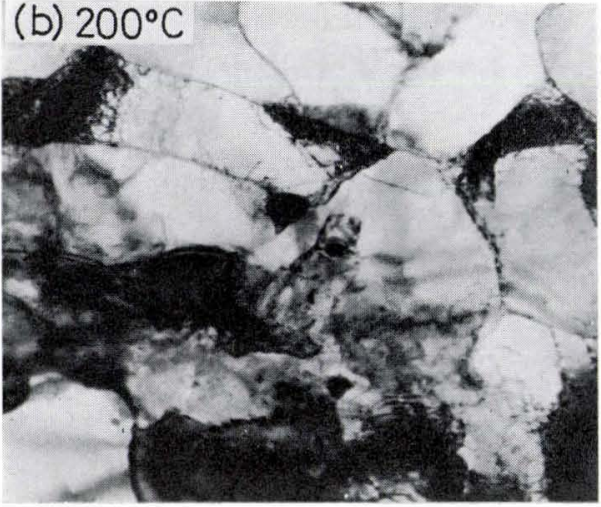

(b)

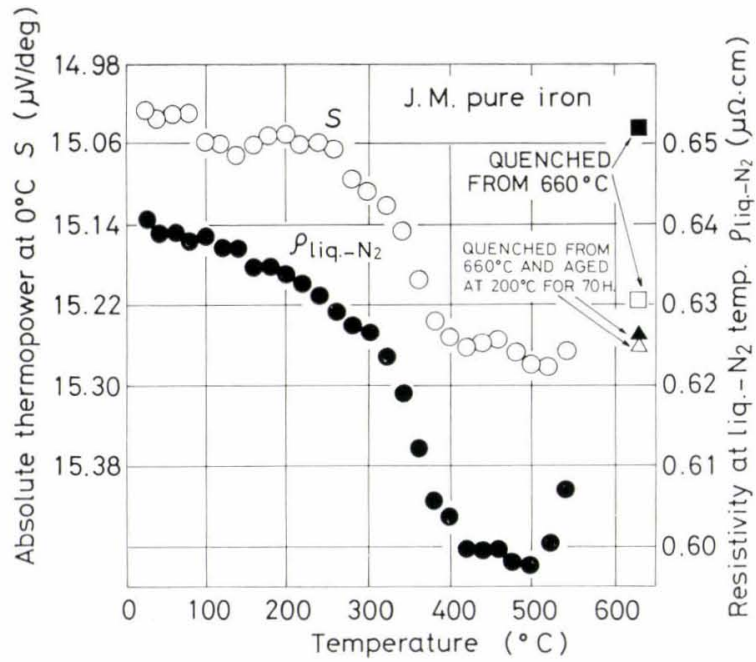

Fig. 7. Variations in the absolute thermopower and the resistivity for J.M.-iron on isochronal annealing for 30-min periods in 20-deg intervals. Concerning the open and filled square and triangle marks, see the text.

graphs of Elect.-iron isochronally annealed up to $100^{\circ} \mathrm{C}, 200^{\circ} \mathrm{C}, 300^{\circ} \mathrm{C}$ and $420^{\circ} \mathrm{C}$, respectively. After annealing at $100^{\circ} \mathrm{C}$, dislocation-free regions are also found in this specimen, but they are not so wide as those observed in J.M.-iron. At $200^{\circ} \mathrm{C}$, a welldefined subgrain structure develops as shown in Photo. 3 (b), indicating that recovery or the rearrangement of dislocations has taken place. On annealing up to $300^{\circ} \mathrm{C}$, recrystallization commences as shown in Photo. 3 (c). At $420^{\circ} \mathrm{C}$, where the softening arrests for a while, unrecrystallized regions still remain as shown in Photo. 3 (d).

The absolute thermopower and the electrical resistivity of J.M.-iron have been plotted against annealing temperature as shown in Fig. 7. The thermopower exhibits a wavy variation on annealing from $40^{\circ} \mathrm{C}$ up to $260^{\circ} \mathrm{C}$, where the resistivity decreases almost monotonously. Such a difference in behaviour between the thermopower and the resistivity cannot be explained on the basis of our present knowledge on the annealing processes in pure iron, e.g., the annihilation of dislocations, the segregation of interstitial solute atoms into dislocations, the precipitation of carbides and nitrides, and so on. The contribution of the vacancies to the thermopower of pure iron has not yet been known. In the case of copper, ${ }^{11,12)}$ it has been reported that the dislocations make a positive contribution, whereas the vacancies make a negative contribution to the electron-diffusion thermopower. The peculiar variation of thermopower in the lowtemperature range may possibly be explained as a phenomenon involving the annihilation of vacancies formed by severe cold working. The literature data on the temperature range in which the vacancies in alpha iron easily migrate have been reported to be around $220 \mathrm{~K},{ }^{13,14)}$ near room temperature, ${ }^{15)}$ and around $700 \mathrm{~K} .^{16,17)}$ Most of them concerned with specimens irradiated by fast-neutrons or fast-electrons and few studies have been made on the behaviour of vacancies in alpha iron generated by severe cold working. The peculiar variation of thermopower in the low-temperature range is a problem left for future studies in relation to the behaviour of vacancies. A brief discussion will be given later.

Considering from the observation by transmission 
electron microscopy and the hardness data given in Fig. 6, the pronounced changes both in the thermopower and the resistivity from around $280^{\circ} \mathrm{C}$ to $420^{\circ} \mathrm{C}$ can be regarded as due to the decrease in dislocation density with the progress of recrystallization. There is an arrest around $420^{\circ} \mathrm{C}$ that corresponds to that observed in the softening curve shown in Fig. 6.

The increase in resistivity and the delayed decrease in thermopower on annealing above $520^{\circ} \mathrm{C}$ were unexpected results. It was supposed that this phenomenon may have been caused by the dissolution of some impurities, probably carbon dissociated from the vacuum pump oil and nitrogen from air, most of which may have been introduced during the prior steps of isochronal annealing. In order to magnify this phenomenon, the test-piece was further heated up to $660^{\circ} \mathrm{C}$ after finishing the isochronal annealing up to $540^{\circ} \mathrm{C}$, kept for $1 \mathrm{hr}$ and quenched into water. The thermopower and the resistivity of the quenched test-piece are shown in Fig. 7 by open and filled square marks, respectively. Then the quenched testpiece was aged at $200^{\circ} \mathrm{C}$ for $70 \mathrm{hr}$. After ageing, the thermopower and the resistivity shifted to the values marked by open and filled triangles in Fig. 7. The difference between the resistivity of $0.6520 \mu \Omega \cdot \mathrm{cm}$ after quenching from $660^{\circ} \mathrm{C}$ and that of $0.6261 \mu \Omega \cdot \mathrm{cm}$ after ageing at $200^{\circ} \mathrm{C}$ is obviously due to the precipitation of carbides and/or nitrides. This difference of $0.0259 \mu \Omega \cdot \mathrm{cm}$ corresponds to $8.8 \mathrm{wt}$.ppm carbon or 9.4 wt.ppm nitrogen provided that the electrical resistivity contribution of carbon is $29.5 \mu \Omega \cdot \mathrm{cm}$ per weight percent $\mathrm{t}^{8)}$ and that of nitrogen is $27.7 \mu \Omega \cdot \mathrm{cm}$ per weight percent. ${ }^{18)}$ The resistivity of the starting test-piece of J.M.-iron was $0.5948 \mu \Omega \cdot \mathrm{cm}$ (Fig. 4). The resistivity after ageing at $200^{\circ} \mathrm{C}$ is $0.0313 \mu \Omega \cdot \mathrm{cm}$ higher than that of the starting test-piece. This corresponds to $10.6 \mathrm{wt} . \mathrm{ppm}$ carbon or $11.3 \mathrm{wt} . \mathrm{ppm}$ nitrogen in solution. The former value of $10.6 \mathrm{wt}$. ppm carbon is much higher than the solubility of cementite in alpha iron at $200^{\circ} \mathrm{C}, 0.84 \mathrm{wt} . \mathrm{ppm}$ carbon, calculated from Wert's equation: ${ }^{19)}$

$$
\mathrm{wt} \% \mathrm{C}=2.55 \exp [-9700 / R T]
$$

though it is lower than the solubility of $\varepsilon$-carbide at $200^{\circ} \mathrm{C}, 17$ wt.ppm carbon, calculated from Chipman's equation $^{20)}$

$$
\mathrm{wt} \% \mathrm{C}=1.15 \exp [-6110 / R T]
$$

The value of $11.3 \mathrm{wt} . \mathrm{ppm}$ nitrogen estimated above is lower than the solubility of $\mathrm{Fe}_{4} \mathrm{~N}$ in alpha iron at $200^{\circ} \mathrm{C}$, 30 wt.ppm nitrogen, calculated from the following equation: ${ }^{21)}$

$$
\mathrm{wt} \% \mathrm{~N}=5.64 \exp [-7090 / R T]
$$

The coexistence of $\varepsilon$-carbide with cementite and $\mathrm{Fe}_{4} \mathrm{~N}$ after the $70 \mathrm{hr}$ ageing at $200^{\circ} \mathrm{C}$ could not be confirmed, but it was believed that a ternary $\mathrm{Fe}-\mathrm{Fe}_{3} \mathrm{C}-\mathrm{Fe}_{4} \mathrm{~N}$ equilibrium had been attained after the ageing. Considering from the inconsistency between the concentration of carbon or nitrogen in solution estimated under the assumption of binary equilibrium and the solubility of cementite, $\varepsilon$-carbide or $\mathrm{Fe}_{4} \mathrm{~N}$ in alpha iron, and also from a hypothetical ternary phase diagram of $\mathrm{Fe}-$ $\mathrm{Fe}_{3} \mathrm{C}-\mathrm{Fe}_{4} \mathrm{~N}$ system, ${ }^{1)}$ the authors concluded that the increase in resistivity on annealing above $520^{\circ} \mathrm{C}$ may have been caused by the dissolution of both nitrogen and carbon introduced during the prior steps of isochronal annealing, although the possibility of contamination by other minor impurities could not be disproved conclusively. It is worth notice that the thermopower shows a low response while the electrical resistivity shows a high response to the reactions which occurred on annealing at $660^{\circ} \mathrm{C}$ and on ageing at $200^{\circ} \mathrm{C}$.

The annealing process of Elect.-iron is shown in Fig. 8. A peculiar variation in thermopower on annealing from $40^{\circ} \mathrm{C}$ up to $200^{\circ} \mathrm{C}$ is also observed, though it is not so pronounced as in the case of J.M.-iron. Steep variation both in thermopower and in resistivity above $340^{\circ} \mathrm{C}$ must be due to the decrease in dislocation density accompanied with recrystallization. An arrest around $420^{\circ} \mathrm{C}$ is also observed. The effect of contamination probably by nitrogen and carbon similar to that observed in J.M.-iron is also manifested in Fig. 8. The resistivity of the starting test-piece of Elect.-iron was $0.6465 \mu \Omega \cdot \mathrm{cm}$ (Fig. 5). The resistivity after ageing at $200^{\circ} \mathrm{C}$ for $70 \mathrm{hr}$ is $0.6776 \mu \Omega \cdot \mathrm{cm}$, which is higher than that of the starting test-piece by 0.0311 $\mu \Omega \cdot \mathrm{cm}$. This value is nearly equal to that of 0.0313 $\mu \Omega \cdot \mathrm{cm}$ mentioned above for J.M.-iron. This suggests that nearly the same state was attained both in J.M.iron and in Elect.-iron after the $70 \mathrm{hr}$ ageing at $200^{\circ} \mathrm{C}$. In Fig. 8 again it is worth notice that the thermopower

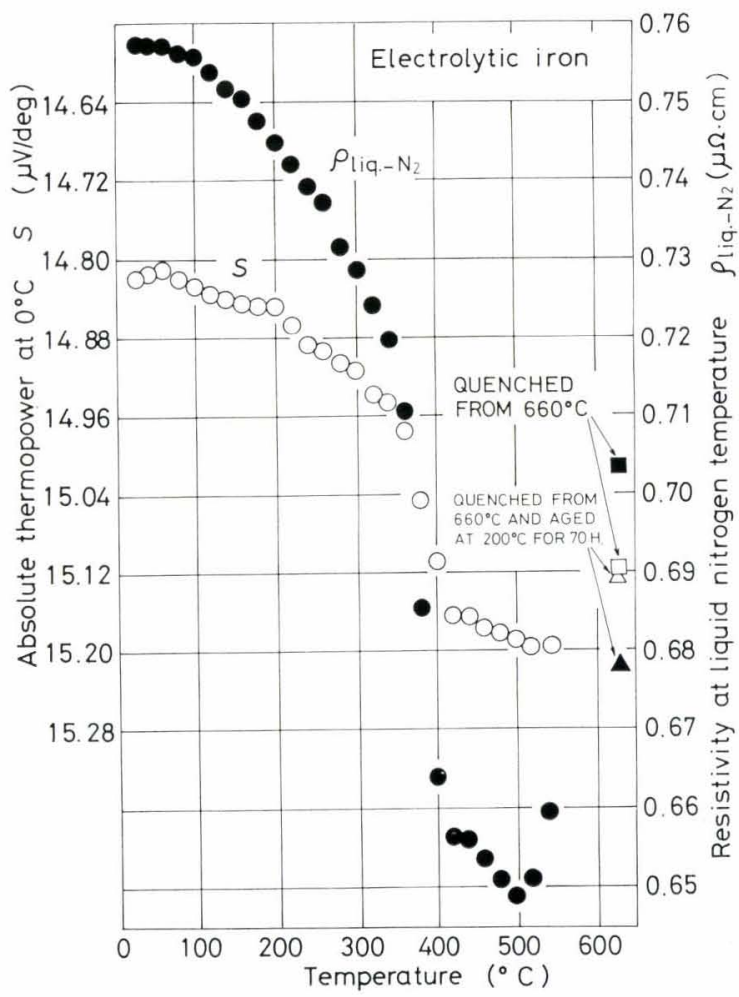

Fig. 8. Variations in the absolute thermopower and the resistivity for Elect.-iron on isochronal annealing for 30-min periods in 20-deg intervals. Concerning the square and triangle marks, see the text. 
is insensitive to the reaction that occurred on ageing at $200^{\circ} \mathrm{C}$.

\section{Thermopower vs. Conductivity Plots at $0^{\circ} \mathrm{C}$}

All the thermopower and the resistivity data for J.M.-iron observed at $0^{\circ} \mathrm{C}$ were summarized into an absolute thermopower vs. electrical conductivity plot. This is shown in Fig. 9. In Figs. 4 and 7, the resistivity data observed at liquid nitrogen temperature have been plotted, yet the values of electrical conductivity at $0^{\circ} \mathrm{C}, 1 / \rho_{0}^{\circ} \mathrm{C}$, are adopted for Fig. 9. The data points for the cold rolling process and the annealing process are marked by open and filled circles, respectively.

Most of the data points for the cold rolling process and those for the process of isochronal annealing from $240^{\circ} \mathrm{C}$ up to $500^{\circ} \mathrm{C}$ fall into a band with a gradient of $500 \pm 100 \mu \mathrm{V} \cdot \mu \Omega \cdot \mathrm{cm} \cdot \mathrm{deg}^{-1}$. This gradient may be said to be the average gradient characteristic to the dislocations.

By surveying finer details of the plot, it can be pointed out that the gradient of a line connecting the data points for cold rolling reductions from $52.8 \%$ to $84.6 \%$ is smaller than that for the lower reductions. The reason for the smaller gradient at higher cold reductions is obscure since the thermopower contributions of various lattice defects in pure iron are unknown. However, on the basis of our knowledge concerning the lattice defects generated by cold working at room temperature, the dislocations and the vacancies (and probably also clusters of vacancies) are considered to be main contributors to the structuresensitive properties of cold-worked pure iron. It has also been said ${ }^{22}$ ) that a high concentration of vacancies detectable by electrical resistivity measurement is produced by severe cold working. In the present experiment also it is believed that a high concentration of vacancies must have been produced during the later stages of cold rolling. This would give rise to a change in the gradient of the thermopower $v s$. conductivity plot. However, the thermopower contribution of the vacancy in iron is unknown. In the case of cop-

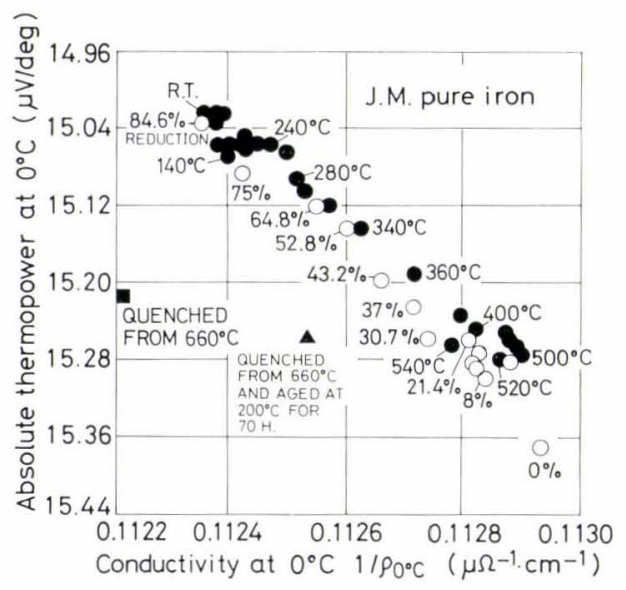

$\bigcirc$ : the process of cold rolling

- : the process of isochronal annealing

Fig. 9. The absolute thermopower vs. conductivity plot at $0^{\circ} \mathrm{C}$ for J.M.-iron per, ${ }^{11,12)}$ it has been known that the electron-diffusion thermopower of the dislocation is a positive value, whereas that of the vacancy is a negative value. Such a drastic difference between the thermopower contribution of the dislocation and that of the vacancy is not necessarily expected in the case of iron, since the thermopower of iron is supposed to contain a considerable amount of the magnon-drag component. ${ }^{5,7}$ ) However, it may at least be said that the gradient of the thermopower vs. conductivity plot characteristic to the vacancy will differ from that characteristic to the dislocation. If we assume that the gradient characteristic to the vacancy is smaller than that characteristic to the dislocation, the smaller gradient at the higher cold reductions could be interpreted qualitatively as due to the generation of a high concentration of vacancies.

In this connection, it should also be pointed out that, in Fig. 9, an almost horizontal line can be drawn through the data points for isochronal annealing from $140^{\circ} \mathrm{C}$ up to $240^{\circ} \mathrm{C}$. This fact seems not to be explained by any annealing reaction ever known. The annealing stage observed in pure iron or dilute carboniron alloys in a temperature range between $140^{\circ} \mathrm{C}$ and $250^{\circ} \mathrm{C}$ has been ascribed by several investigators ${ }^{22-26)}$ to that associated with the precipitation of cementite. Needless to say, the authors at first speculated that the $140^{\circ} \mathrm{C} \sim 250^{\circ} \mathrm{C}$ stage observed in our J.M.-iron specimen may also have been caused by the precipitation of cementite. It was found that the change in resistivity due to the dissolution of cementite was actually included as a minor change in the present data. As stated before, the starting test-piece of J.M.iron had contained cementite corresponding to $0.5 \mathrm{wt}$. ppm carbon. This cementite would rapidly dissolve into the iron matrix on annealing at temperatures just below $175^{\circ} \mathrm{C}$ where the solubility of cementite in alpha iron is $0.5 \mathrm{wt} . \mathrm{ppm}$. (The solubility was calculated by Wert's equation. ${ }^{19}$ ) In fact, the plot of the resistivity shown in Fig. 7 reveals an anomaly in a temperature range between $100^{\circ} \mathrm{C}$ and $160^{\circ} \mathrm{C}$. Provided that the electrical resistivity contributions of $1 \mathrm{wt} . \%$ of carbon in interstitial sites and in dislocation sites are $29.5 \mu \Omega \cdot \mathrm{cm}$ and $7.7 \mu \Omega \cdot \mathrm{cm},{ }^{8)}$ respectively, the dissolution of $0.5 \mathrm{wt} . \mathrm{ppm}$ carbon into the dislocation sites of the iron matrix would cause an increase of $0.0011 \mu \Omega \cdot \mathrm{cm}$ in the resistivity. The anomaly observed in the range between $100^{\circ} \mathrm{C}$ and $160^{\circ} \mathrm{C}$ nearly corresponds to this value. The resistivity change due to the dissolution of cementite into the iron matrix is too small to interpret the observed change of resistivity in the annealing stage between $140^{\circ} \mathrm{C}$ and $240^{\circ} \mathrm{C}$. Thus, neither the dissolution nor the precipitation of cementite is responsible to the $140^{\circ} \mathrm{C} \sim 240^{\circ} \mathrm{C}$ stage. Following the argument stated above, the authors have been compelled to suppose that the $140^{\circ} \mathrm{C} \sim 240^{\circ} \mathrm{C}$ stage would presumably be due to the annihilation of vacancies. To rationalize such a conclusion, the gradient characteristic to the vacancy should be a negative value. If the gradient characteristic to the vacancy is a negative value, not only the gradient of the $140^{\circ} \mathrm{C} \sim 240^{\circ} \mathrm{C}$ stage but also the gradi- 
: the process of cold rolling

: the process isochronal annealing Fig. 10 .

The absolute thermopower vs. conductivity plot at $0^{\circ} \mathrm{C}$ for Elect.-iron.

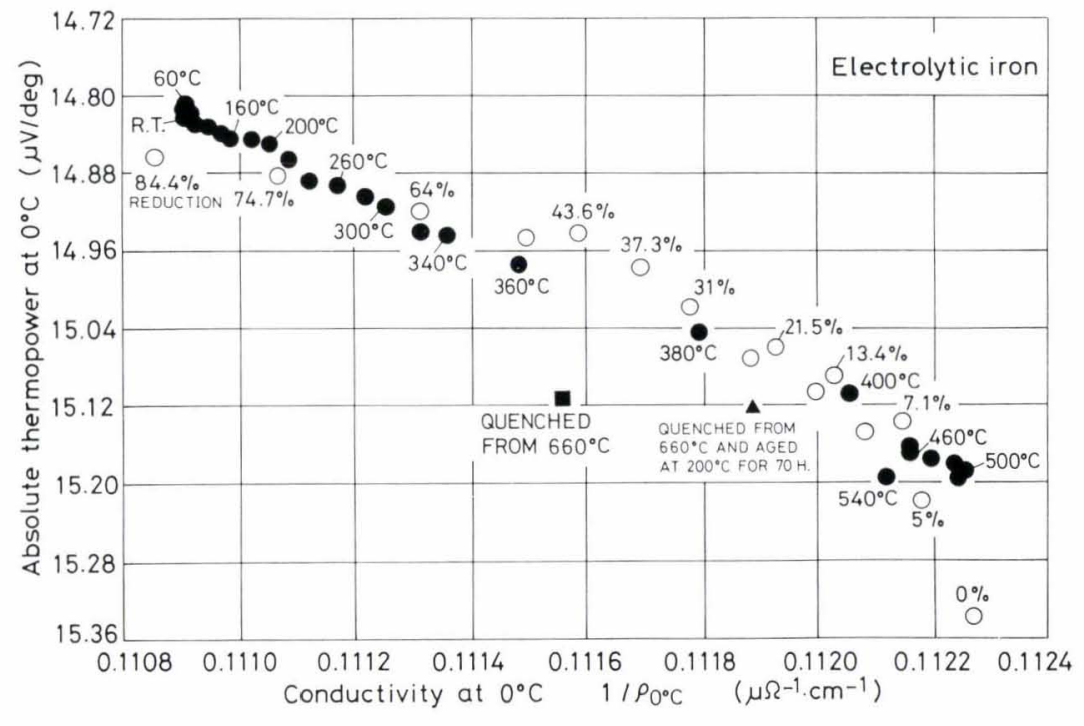

ent for higher cold reductions mentioned above could be explained by the behaviour of vacancies. Since we have no theoretical basis for the gradient characteristic to the vacancy, further experiments are required on the thermopower of pure iron after severe cold working to determine the gradient characteristic to the vacancy.

In Fig. 9, the data points after isochronal annealing above $500^{\circ} \mathrm{C}$, after quenching from $660^{\circ} \mathrm{C}$ (the filled square mark) and after ageing at $200^{\circ} \mathrm{C}$ (the filled triangle mark) can approximately be fitted on a straight line with a small gradient (about $100 \mu \mathrm{V}$. $\left.\mu \Omega \cdot \mathrm{cm} \cdot \mathrm{deg}^{-1}\right)$. On the basis of the discussion given in the preceding section, this may presumably be the gradient characteristic to the interstitial atoms of carbon and nitrogen in solution.

The absolute thermopower vs. electrical conductivity plot for Elect.-iron at $0^{\circ} \mathrm{C}$ is shown in Fig. 10 . As stated before, the cold rolling process of Elect.-iron could be divided into three regions which are also noticed in Fig. 10. The first region below $7.1 \%$ reduction is characterized by a steep gradient in the plot. For the interpretation of this steep gradient, it should be noted that the concept of vector analysis is generally applicable to such a linear system as the thermopower $v s$. conductivity plot, though this concept has already been included in the preceding discussion on the effect of vacancies. In a thermopower $v s$. conductivity plot, a vector of a process composed of several reactions is a sum of the vector components of these reactions involved. ${ }^{27}$ A simple consideration has led to a conclusion that the steep gradient in the low-reduction range can be explained by the overlapping of two reactions: the multiplication of dislocations and simultaneous segregation of a small amount of nitrogen and carbon into the newly formed dislocations.

In the second region from about $10 \%$ to $43.6 \%$ reductions, the gradient is approximately $400 \mu \mathrm{V} \cdot \mu \Omega$. $\mathrm{cm} \cdot \mathrm{deg}^{-1}$. This gradient may presumably be that characteristic to the dislocation in Elect.-iron, though the reason why it is smaller than the average gradient in the case of J.M.-iron is unclear. The third region above $43.6 \%$ reduction has a smaller gradient and this may be assumed to be as a result of the formation of a high concentration of vacancies by severe cold working on the basis of the same reasoning stated in the case of J.M.-iron.

After cold rolling to a reduction of $84.4 \%$, the testpiece was left for about one month at room temperature. In Fig. 10, the open circle noted as " $84.4 \%$ " is the data point immediately after cold rolling and the filled circle noted as "R.T." is the data point after keeping for about one month at room temperature. Thus, on keeping (or ageing) at room temperature, the data point shifted with a steep negative gradient. Such a shift can hardly be detected in the case of J.M.-iron as shown in Fig. 9. The reason for this shift found in Elect.-iron is an unsolved problem. It may be a phenomenon resulting from the formation of carbon-vacancy complexes or trapping of carbon atoms into the vacancies.

The gradient for the annealing stage from $160^{\circ} \mathrm{C}$ to $200^{\circ} \mathrm{C}$ is very small and this may be explained on the basis of the same reasoning as stated in the case of J.M.-iron as due to the annihilation of vacancies. The annealing stage from about $240^{\circ} \mathrm{C}$ to $400^{\circ} \mathrm{C}$, during which a drastic decrease in dislocation density occurs, has a gradient of $240 \mu \mathrm{V} \cdot \mu \Omega \cdot \mathrm{cm} \cdot \mathrm{deg}^{-1} \mathrm{much}$ smaller than that for J.M.-iron or that for the second region of the cold rolling process. From our recent work $^{27)}$ this has been attributed to the decrease in the density of dislocations into which the carbon atoms have segregated. The annealing stage between $400^{\circ} \mathrm{C}$ and $500^{\circ} \mathrm{C}$ has almost the same gradient as that for the second region of cold rolling.

As in the case of J.M.-iron, the gradient of a line connecting the data points after the isochronal annealing above $500^{\circ} \mathrm{C}$, after quenching from $660^{\circ} \mathrm{C}$ and after ageing at $200^{\circ} \mathrm{C}$ is small and it can also be regarded to correspond to carbon and nitrogen in solution. The gradient is $130 \pm 50 \mu \mathrm{V} \cdot \mu \Omega \cdot \mathrm{cm} \cdot \mathrm{deg}^{-1}$. This seems to be a reasonable value, because it lies between that observed by Nagakura $\left.{ }^{28}\right)$ for the precipitation of nitride in iron $\left(90 \pm 30 \mu \mathrm{V} \cdot \mu \Omega \cdot \mathrm{cm} \cdot \mathrm{deg}^{-1}\right)$ and that of the previous paper ${ }^{1)}$ for the carbon in solu- 
tion in a commercial low-carbon aluminium-killed steel $\left(270 \pm 50 \mu \mathrm{V} \cdot \mu \Omega \cdot \mathrm{cm} \cdot \mathrm{deg}^{-1}\right)$.

\section{Summary}

Decarburized and denitrided specimens of JohnsonMatthey's pure iron and of electrolytic iron were cold rolled at room temperature by successive passes of low reductions to a total reduction of about $85 \%$ in thickness. After keeping for about one month at room temperature, the $85 \%$-rolled specimens were isochronally annealed at $30 \mathrm{~min} / 20^{\circ} \mathrm{C}$ step up to $540^{\circ} \mathrm{C}$. The variations in the hardness, the electrical resistivity and the absolute thermopower during these processes have been observed. The data of thermopower and resistivity observed at $0^{\circ} \mathrm{C}$ were summarized into thermopower vs. conductivity plots. The microstructures at several stages of the processing were also observed by transmission electron microscopy. The following results have been obtained.

(1) In Johnson-Matthey's iron, the work-hardening by cold rolling had a tendency to saturate above $50 \%$ reduction, whereas the dislocation density continued to increase. This phenomenon was partly attributed to the effect of texture formation. From the thermopower vs. conductivity plot, it was supposed that a high concentration of vacancies was generated in the later stages of cold rolling.

(2) The gradient of the thermopower $v s$. conductivity plot characteristic to the dislocation was $500 \pm 100 \mu \mathrm{V} \cdot \mu \Omega \cdot \mathrm{cm} \cdot \mathrm{deg}^{-1}$ for Johnson-Matthey's iron, and was $400 \mu \mathrm{V} \cdot \mu \Omega \cdot \mathrm{cm} \cdot \mathrm{deg}^{-1}$ for electrolytic iron.

(3) The cold rolling process of electolytic iron could be divided into three regions. The first region was considered to be accompanied with the segregation of nitrogen and carbon atoms into dislocations. The second region being mainly governed by the increase in the dislocation density, the third one was supposed to be influenced by the formation of vacancies.

(4) It was supposed that the vacancies generated by severe cold rolling annihilated in a temperature range between $140^{\circ} \mathrm{C}$ and $240^{\circ} \mathrm{C}$ in Johnson-Matthey's iron, and between $160^{\circ} \mathrm{C}$ and $200^{\circ} \mathrm{C}$ in electrolytic iron.

(5) Softening by recrystallization commenced at about $340^{\circ} \mathrm{C}$ in Johnson-Matthey's iron, while at about $360^{\circ} \mathrm{C}$ in electrolytic iron. In both specimens, an arrest of softening was observed at about $420^{\circ} \mathrm{C}$.

(6) The gradient of the thermopower vs. conductivity plot characteristic to carbon and nitrogen in solution was $130 \pm 50 \mu \mathrm{V} \cdot \mu \Omega \cdot \mathrm{cm} \cdot \mathrm{deg}^{-1}$.

\section{REFERENCES}

1) H. Abe, Tak. Suzuki, and O. Furukimi: Tetsu-to-Hagané, 63 (1977), 971.

2) H. Abe, Tak. Suzuki and H. Hoshina: Tetsu-to-Hagané, 63 (1977), S331.

3) L. Nordheim and C.J. Gorter: Physica, 2 (1935), 283.

4) R. P. Huebener: Solid State Physics, 27 (1972), 63.

5) F. J. Blatt, D. J. Flood, V. Rowe and P. A. Schroeder: Phys. Rev. Letters, 18 (1967), 395.

6) F.J. Blatt: Can. J. Phys., 50 (1972), 2836.

7) F.J. Blatt, P. A. Schroeder, C. L. Foiles and D. Greig: Thermoelectric Power of Metals, Plenum Press, New York, (1976).

8) G. R. Speich: Trans. Met. Soc. AIME, 245 (1969), 2553.

9) H. Wagenblast and S. Arajs: J. Appl. Phys., 39 (1968), 5885 .

10) L.J. Cuddy: Phil. Mag., 12 (1965), 855.

11) F.J. Blatt: Phys. Rev., 100 (1955), 666.

12) H. Abe, F. Togawa and Y. Ohashi: J. Japan Inst. Met. 40 (1976), 201

13) L.J. Cuddy: Acta Met., 16 (1968), 23.

14) S. Tanigawa, K. Hinode, H. Kumakura, M. Doyama and S. Okuda: Preprints of the 81st Meeting of Jap. Inst. Metals, (1977), 58.

15) E. Kuramoto, K. Kitajima, T. Chiba, and K. Tsuda: Preprints of the 82nd Meeting of Japan Inst. Metals, (1978), 177.

16) M. Kiritani and T. Takata: Proc. Intern. Conf. on Properties of Atomic Defects in Metals, Argonne, (1976); submitted to $J$. Nuclear Mat.

17) K. Yamakawa: Bull. Jap. Inst. Metals, 16 (1977), 490.

18) H. Wagenblast and S. Arajs: Phys. Stat. Sol., 26 (1968), 409.

19) C. A. Wert: Trans. AIME, 188 (1950), 1242.

20) J. Chipman: Met. Trans., 3 (1972), 55.

21) R. Rawlings and D. Tambini: JISI, 184 (1956), 302.

22) J. Takamura, I. Takahashi and M. Amano: Trans, ISIJ, 9 (1969), 216.

23) F. E. Fujita and A. C. Damask: Acta Met,. 12 (1964), 331

24) W. Glaeser and H. Wever: Phys. Stat. Sol., 35 (1969), 367.

25) F. Ichikawa, K. Yamakawa, and F. E. Fujita: Script. Met. 6 (1972), 929.

26) H. Wever and W. Seith: Phys. Stat. Sol., (a) 28 (1975), 187.

27) H. Abe and Tak. Suzuki: unpublished work.

28) K. Nagakura: Private communication (Feb. 24, 1975). 